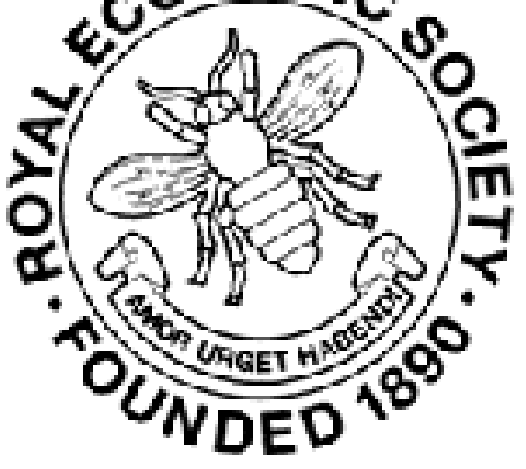

\title{
Laws of Increasing and Decreasing Returns in Production and Consumption
} Author(s): S. J. Chapman

Source: The Economic Journal, Vol. 18, No. 69 (Mar., 1908), pp. 52-59

Published by: Wiley on behalf of the Royal Economic Society

Stable URL: http://www.jstor.org/stable/2221208

Accessed: 27-06-2016 09:12 UTC

Your use of the JSTOR archive indicates your acceptance of the Terms \& Conditions of Use, available at

http://about.jstor.org/terms

JSTOR is a not-for-profit service that helps scholars, researchers, and students discover, use, and build upon a wide range of content in a trusted digital archive. We use information technology and tools to increase productivity and facilitate new forms of scholarship. For more information about JSTOR, please contact support@jstor.org.

Royal Economic Society, Wiley are collaborating with JSTOR to digitize, preserve and extend access to The Economic Journal 


\section{LAWS OF INCREASING AND DECREASING RETURNS IN PRODUCTION AND CONSUMPTION.}

THE distinction between economic laws grounded upon reasoning from fundamental data, which relate to abstractions, and those dependent upon observation of the general course of events, which relate more directly to actual affairs, is commonly recognised. For convenience I shall term the first "formal" or "abstract" laws, and the latter " material" or "realistic " laws. We shall be concerned here only with the former." I suggest that the terms "formal law of increasing returns" and "formal law of decreasing returns" should be applied, in their relation to production, to universal statements regarding the effect upon quantity of output of variations in the quantity and arrangements of agents or factors, apart from the influence of facts connected with the supply of agents and variations of the ratio between the several qualities of each. Any laws purely of production must, of course, refer to the output measured in kind and not in money. The value of the product is a function also of demand, and a law purely of production must be true independently of laws of demand. The generalisations sought are intended to be static, in the sense that their truth is not dependent upon progress in knowledge or invention. Interesting dynamic uniformities could be formulated, but these are not our present objective.

I shall now attempt to assign a precise meaning to the " formal law of increasing returns." It will be generally agreed, or at

1 The latter, of course, cannot partake of universality in the same degree as the former, which by abstraction rule out disturbing factors. Professor Marshall, following English tradition, understands by the "laws of increasing and diminishing returns" realistic uniformities.' Thus he writes (pp. 318-9, Principles, 5th Ed.), "We say broadly that while the part which nature plays in production shows a tendency to diminishing return, the part which man plays shows a tendency to increasing return. The law of increasing return may be worded thus : An increase of capital and labour leads generally to an improved organisation, which increases the efficiency of the work of capital and labour." With these uniformities I am not dealing, except in so far as they receive deductive support from more fundamental generalisations. 
least suspected, that the conditions and effects of specialisation lie at the root of any such law. Specialisation indicates (1) a restriction of the purpose to which a given factor is applied, and, sometimes, in addition (2) a change undergone by the factor whereby it is enabled to perform better its limited function. Even if the agent is not adapted to its end by alteration of its character, economy may result (a) from the closer correspondence between capacity in the agent and its task, which is rendered possible by restriction of the offices of each agent (it being supposed that differences exist between the units, or some of them, of each group of factors); or (b) from some saving of the time spent in agents periodically changing from one task to another. From these considerations it would appear that the following statement is universally true, though actually in some cases the gain from the greater specialisation might be insignificant:-The greater the degree of specialisation within a class of factors the greater is the efficiency of the class, other things being equal. Another uniformity may also be affirmed, namely, that as the quantity of a factor in production is increased its productive power per unit tends to be raised-owing to the wider scope offered for specialism.

By deduction from these fundamental truths we may now proceed to formulate the law of which we are in search. Evidently, were no further specialisation to result from the all-round proportionate enlargement of a group of factors engaged in turning out a given product, the product would increase at the same rate as the factors. This would merely be a case of reduplicating existing productive systems, and identical causes have identical effects. But, since every multiplication of factors broadens the scope for specialism, we may affirm what I should propose to call the formal law of increasing returns, ${ }^{1}$ that if factors in production be proportionately increased by successive increments the corresponding marginal outputs will tend to rise. ${ }^{2}$

1 I use increasing and decreasing returns in the sense given to them by Prof. Edgeworth in Economic JournaL, Vol. ix., p. 294.

2 The objection might be raised that at some stage the greater complexity of arrangement entailed by increased specialism might stop further specialism, and that therefore constant returns might be reached, though decreasing returns never could be. To this contention it would seem to be an adequate response that, inasmuch as ex hypothesi the quantity of all factors is added to, more specialism could always be secured without greater complexity per unit of organising power resulting. Further, the consequent specialisation of the organising power would raise its efficiency. However, it is of course highly improbable that a proportionate increase of all the factors will lead to a larger return than could be procured by any conceivable disproportionate increases involving the same cost, even though it be assumed that the arrangement of factors was the most economical possible at the starting point. 
It is more difficult to frame a satisfactory uniformity relating to decreasing returns. Decreasing returns, when regarded on the same formal plane as increasing returns, are found to be connected with certain disproportionate variations of the factors in production but not with all disproportionate variations. If of a group of factors, a part (which does not exhaust all the necessary ${ }^{1}$ constituents of the group) be increased by successive and similar increments, any increase of the output must in time take place at a decreasing rate, and finally the output must begin to diminish. The truth of this statement follows from the fact that after a time the scarcity of the necessary factor, or factors, kept constant would increasingly check the expression of the powers of the augmented factors, until finally an additional increment would prove only an encumbrance. ${ }^{2}$ Obviously increasing potential efficiency on the part of the augmented factors could not indefinitely counteract the decreasing returns so brought about. However, observe that decreasing returns do not necessarily appear at once in the circumstances supposed, as increasing returns would if the same group of factors were augmented proportionately. ${ }^{3}$ First increasing returns might be witnessed; and it is conceivable that, following upon a period of decreasing returns, increasing returns might be met with, and even recur after a relapse to decreasing returns, before the ultimate stage of decreasing returns was reached. ${ }^{4}$ Hence the formal law of decreasing returns must

1 The word "necessary" has had to be introduced, as otherwise a factor which could be dispensed with might be taken as the constant part, and in this case the increase proportionally of the remainder might eventually cause increasing returns.

2 I assume that no factor exists, the use of excessive quantities of which would cause no inconvenience. It is understood that part of a factor cannot be ignored. (See next note.)

3 Actually, specialisation being supposed inoperative, diminishing returns would tend to be experienced from the outset, because an employer would put a factor to its most serviceable use even if entire neglect of some portion of the other factors were involved. Thus Robinson Crusoe would have set Friday to till such an area of ground as would have yielded the maximum harvest attainable by Friday's labour. He would never have dreamt of making Friday spread his labour evenly over the whole island. If he had made-Friday work in this way then the immigration of more Fridays would have resulted in increasing returns for a time, apart from the division of labour. In laying down the formal law we assume that Robinson Crusoe must in the first instance try to work the whole island. If swarms of Fridays crowded to the island the new-comers would after a time retard instead of helping those at work there.

4 Thus, the costs of all factors being supposed constant, it is possible that for a given expenditure there might be several arrangements of agents yielding maxima results all of which maxima need not be of the same amount. By " maxima" here I mean results, greater than any attained by making small variations in any direction from the positions indicated, the total cost being kept constant. Variations in any direction, on the condition of the same total cost being retained, 
be phrased as follows, if it is desired to keep it complementary in form to the formal law of increasing returns, and to frame it so as to express our full knowledge of the conditions of decreasing returns :-If of a group of factors, a part (which does not exhaust all the necessary constituents of the group) be increased, the increase of the output must in time take place at a decreasing rate, and finally the output must begin to diminish, but before the ultimate stage of decreasing marginal returns is reached increasing marginal returns may be experienced, or results oscillating from increasing to decreasing marginal returns.

II.

I propose next by analysis of the actual production of commodities to elicit its forms with a view to determining the unitary factors in the several fields wherein the laws of increasing and decreasing returns are in operation. In all production of commodities the agents (of which there must be more than one, for there must be at least labour and material or land) tend to be united in a hierarchy of systems. We may distinguish :-

Systems of the First Order.-These are individual businesses, whether manufacturing or agricultural, or of other kinds. Usually in manufacturing each business means one factory, but it may include more than one. Some businesses comprising more than one factory are not readily classified. To meet the difficulty systems of sub-orders might be admitted; but here I pretend only to sketch. In a highly differentiated community it is exceedingly probable that several forms will co-exist among systems of the first order producing the same thing. Each will indicate a position of stable equilibrium. ${ }^{1}$

Now it is clear, from the exposition already given of the formal laws of increasing and decreasing returns, that if any part (which does not exhaust the necessary constituents) of a system of the first order be continuously augmented, the product will be obtained at some stage at a decreasing rate. Further, it is clear that the same effect must ultimately succeed the continuous

would meet at first with decreasing returns, though they might occasion eventually increasing returns for a time.

1 There cannot, therefore, be any continuous mutation of one such form into another. Any system could only pass continuously into another through an avenue of losses which would at first expand and then contract. More advantageous systems are approached only through fundamental reconstructions and then realised in detail by the operation of the law of substitution, the proportions of factors being varied till their marginal worths in relation to cost are equal. Other things remaining the same, the more advantageous system once reached tends to supplant the less advantageous. 
all-round expansion of a system of the first order (the growth proportionately of an individual business, including material, \&c., used), on the assumption that the employer is strictly necessary, for there would be limitation of the directing power. If the employer is not to be regarded as strictly necessary, then it can be deduced from our formula that though the ultimate effect would tend to be increasing returns, the penultimate would be decreasing returns. At the point of divergence the effect of the employer would be zero. ${ }^{1}$

Systems of the Second Order.-These are constituted of the many businesses of various kinds (systems of the first order) concerned in the production of some one commodity. ${ }^{2}$ It is evident that a system of the second order is not self-contained within defined boundaries. It is frequently compounded of many " industries," as that term is commonly used, and of portions of others. Industries overlap, parts of one subserving another-pig iron, for instance, is utilised for other objects than steel rails. A system of the second order may be a highly complicated arrangement of specialised industrial businesses linked together by commercial connections. Two broadly distinguishable types may be contrasted : (a) the one wherein a commodity is passed on by purchase to undergo the next finishing process; $(b)$ the other wherein a central business contracts with other and different businesses to perform processes upon its goods. Actually in most cases the two types are found intermingled. Let the industrial processes involved in the production of a commodity $\mathrm{X}$ be $\mathrm{A}, \mathrm{B}$, and $\mathrm{C}$; let dealing functions, with reference to the buying or selling of either commodities or services, be indicated by small letters, and the commercial connections with the providers of raw material on the one hand and consumers on the other hand be omitted; and let the independence of a business be indicated by brackets : then, evidently, in both contrasted types the business units of the system must be one in kind of the form, $(A, B, C)$; or

1 These laws are true, of course, whether at the starting point the arrangement of factors was in position of equilibrium or not. It being assumed that the starting point is such a position of equilibrium, it does not follow that the decreasing returns which refer to the relation between quantity of output and quantitative variations of the factors would operate at once, though the dècreasing returns which refer to the relation between costs of production and value of output would theoretically operate at once. The position of equilibrium is reached by balancing value of product against cost of attaining it, as already stated.

2 "Processes" would naturally be thought of as the next highest units to those recognised in systems of the first order, but the admission of this step in the productive hierarchy had better be withheld in a general treatment because $(a)$ "processes" are not exsily defined, and $(b)$ their separate recognition as units raises no distinct problems. 
three in kind of forms, $(A, a),\left(b, B, b^{\prime}\right),(c, C)$; or five in kind of forms, $(\mathrm{A}),(\mathrm{a}, \mathrm{b}),(\mathrm{B}),(\mathrm{b}, \mathrm{c}),(\mathrm{C})$; or must consist in certain variations between these forms. That is, in so far as specialism in the system takes place by processes, commercial functions may specialise as distinct businesses, or they may remain as wings of the manufacturing businesses. The same analysis might be applied to the relations of a business: with the sellers of material, plant, \&c., and with customers ; and, of course, the commercial ties, binding any industrial business with the whole of which it is a part, may be many.

With regard to the formal laws of increasing and decreasing returns; "businesses" may be taken as the unitary factors in these systems of the second order. Evidently decreasing returns ultimately result, subject to the conditions laid down above, not only from a continuous partial increase of factors within a business, but also from a continuous partial increase of factors (business) within systems of the second order. ${ }^{1}$ Thus, if businesses were added to the spinning branch of the cotton industry, other parts being kept constant, the increase of the product of the manufacturing branch would take place ultimately at a diminishing rate. The gain derived from the greater specialisation of spinning businesses would be counteracted at some stage by the diminishing utility of spinning to the industry as a whole, apart from this specialism. But increasing returns would tend to result from expansion of the industry as a whole; that is to say, if the numbers of businesses of all kinds involved in a system of the second order were proportionately raised, the product would tend to advance at an increasing rate in the long run. ${ }^{2}$ At first the rule would be constant returns because the intenser specialisation of businesses is only brought about very slowly.

It might be thought necessary for logical completeness to introduce here the conception of all the industries of the community as a system of the third order, and if "industry" be understood in the ordinary sense of the term it would be necessary because industries are systematically related to one another for the production of certain articles. According to our terminology here, however, industries so related form a system of the second order.

1 I shall ignore here the distinction, as regards effects, between local and worldwide expansions of an industry with world-wide markets, which I have already discussed to some extent in this Journal, vol. xv., p. 191 et seq.

2 The assumption is made, the reader is reminded, that recourse to a lower quality of factors is not entailed. The chance of the quality of some factors falling off, however, is far from being negligible in industries needing in their factors peculiar qualities supplies of which are limited. 
Industries making different things do not constitute a system at all on the side of production alone, as "production" has been used in this article. They become a system in relation to consumption and supplies of natural agents, because all draw upon these natural agents and all produce to satisfy human demands, and all are rivals, therefore, directly or indirectly, in securing natural agents and disposing of their products.

\section{III.}

Transferring our attention to the problem of consumption, we observe that consumption is organised in systems analogous to those of production. Commodities and services are produced by organised systems of factors, and commodities are demanded grouped in the systematic wholes which constitute the standards of life of persons. The latter we may call systems of consumption of the first order. A system of consumption of the second order would be compounded of these, comprising the consumptionschemes of persons brought directly or indirectly into touch with one another as consumers. Evidently the systems of the second order in consumption are overlapping like systems of the same order in production. Our problem is concerned with the relations between proportionate and disproportionate variations of these systems and the satisfaction derived from consumption.

Does the fundamental law of specialism apply? Clearly it does as regards commodities and services in systems of the first order-and even as regards systems of the first order in a system of the second order in a limited degree, as we shall observe in the concluding paragraph-if commodities be generalised as factors were generalised when we dealt with production. If, for instance, a person can afford to have only one chair, it will be chosen to serve best in general the purposes of rest, meals, and work; but, if he can afford two, they will not be the same but specialised, one, say, as an easy chair and one as a straight-backed chair, and for a special purpose a chair specialised to that purpose will produce more satisfaction than the compromise chair. Again, it is only when his income has passed a certain limit that a person finds it economical to acquire the conveniences, over and above those afforded by hired conveyances, involved in keeping a private carriage; just as certain highly specialised machinery does not become economical to an employer until his business has attained a certain size.

Systems of the first order are identical in consumption and production in that every system of either group has reference to 
a supposed quantitatively invariable individual, the consumer in the one case and the employer in the other. We may at once declare that continuous quantitative variations, whether of the part or the whole, of systems of consumption of the first order must result at some stage in decreasing marginal satisfactions, and finally in a shrinkage of total satisfaction, on the understanding (analogous to the assumption made above that no incorporated agent in production must be ignored) that every commodity or service acquired must be consumed. This may be taken as the full meaning of the law of diminishing utility.

On examining systems of the higher order in consumption we discover that although the organic connections between their parts (systems of the first order), which enable the law of specialism to be predicated, are less than in productive systems of the second order, they exist, nevertheless, to some extent. One instance occurs in relation to "public goods," which can be provided only when the community on a particular spot has reached a certain magnitude. Examples of such " public goods" are parks, libraries, theatres, street lighting, good and pleasant roads, and conveniences in the supply of water and illumination provided for houses. Again, from a large volume of commodities each person will get more exactly what he or she wants, and in consequence more satisfaction, than from a small volume of commodities. Hence the law of increasing returns is true of systems of the higher order. Add proportionately to all the classes in the community, then (both the means of each person to satisfy wants and schemes of consumption being taken as constant) the total satisfaction of the community will tend to rise at an increasing rate. It does not appear, however, that decreasing returns must accompany expansion of systems of consumption of the second order which takes place solely by augmentation of qualitatively distinct branches of these systems, because such branches are subsidiary to one another only in a strictly limited degree. When two commodities, or two qualities of one commodity, are produced jointly, and one is consumed by one class and the other by another class, the growth of the one class only in the community (schemes of consumption and power to get goods being taken as constant in each class) would no doubt necessitate decreasing returns of satisfaction ultimately, were it not for the counteracting influence of increasing returns in satisfaction associated with the growing class. There might, and there might not, be decreasing returns. We are taking no account, observe, of the effects of a growing population upon productive power.

S. J. CHAPMAN 